\title{
A Case Report of a Paediatric Intestinal Evisceration by Road Traffic Accident in Nepal
}

\author{
Shah $\mathrm{T}^{\star}$ \\ Department of General Surgery, Asia Pacific Medical College, Nepal
}

*Corresponding author: Shah T, Assistant Professor, Department of General Surgery, Asia Pacific Medical College, Nepal, E-mail: dr.tuhinshah@gmail.com

Citation: Shah T (2017) A Case Report of a Paediatric Intestinal Evisceration by Road Traffic Accident in Nepal. SAJ Case Rep 4: 305

Article history: Received: 24 July 2017, Accepted: 29 August 2017, Published: 31 August 2017

\begin{abstract}
Road traffic accidents are on a rise with the number of vehicles increasing on the roads every day. With it the morbidity and the mortality associated with such accidents including both the people inside the vehicle and the pedestrians. Here a case report of an 8 year male is described who presented with small bowel evisceration following a motorcycle collision, along with a review of literature. The boy had an uneventful recovery.
\end{abstract}

Keywords: Paediatric; Intestinal; Ecisceration; Small intestine; Abdominal; Surgery; Laparotomy

\section{Case description}

An 8-year-old male was the victim of a motorcycle collision injury when playing near the highway. He was brought to the emergency with minor head injury (Glasgow Coma Score 14/15) as per the GCS and herniation (evisceration) of small intestine about $60 \mathrm{cms}$ through the abdominal wall defect in the right lumbar region [1]. He was hemodynamically stable and required minimal fluid resuscitation. His primary and secondary survey were conducted as per ATLS guidelines. The eviscerated bowel was covered with saline dressings while he waited to go to the operating room, where he was taken within 90 minutes and underwent exploratory laparotomy. The operative findings were an anterior wall defect of size $5 \mathrm{~cm}$ in the right lumbar region with the evisceration of 60 $\mathrm{cms}$ of edematous jejunum. There were two perforations of less than $1 \mathrm{~cm}$ size in the anti-mesenteric border of the jejunum, the first was $60 \mathrm{cms}$ from the duodeno-jejunal flexure and the second perforation was $25 \mathrm{cms}$ distally from the first $(85 \mathrm{cms}$ from the duodeno-jejunal flexure). As per the American Association for the Surgery of Trauma (AAST) the small bowel injury scale was Grade 3 [2]. The perforations were debrided and repaired primarily and the abdominal wall was reconstructed in layers. He made an uneventful recovery.

\section{Discussion}

Abdominal trauma is on a constant rise as a result of an increase in vehicles on the road which is responsible for the escalation in the road traffic accidents. A majority of abdominal injury in children is caused by blunt trauma, with liver and spleen being commonly injured solid organs; and road traffic accidents are the second most common cause $[3,4]$.

Most intestinal eviscerations seen in trauma are caused by stab wounds which require laparotomy [5]. The colon and small intestine are the most commonly injured hollow viscus organs in penetrating injury [6]. Bowel injuries in trauma is a leading cause of morbidity and mortality $[7,8]$.

Apart from the patient's history, symptoms and the clinical signs, the diagnostic modalities to conclude the presence of any GIT perforation would range from radiographs, focused assessment with sonography for trauma (FAST), computed tomography (CT) scan, diagnostic peritoneal lavage (DPL), and diagnostic laparoscopy. If evisceration of abdominal contents is present, the intestine and the contents should be wrapped to minimize further fluid loss, if no active bleed is present. If active bleed present it should be controlled at once. The use of saline soaked swabs to cover the intestine can be used in a hospital setting, other option being the use 
of clean wet clothing or cling film when outside hospital setting. Other injuries should be ruled out as the risk of missing them is high. The herniating intestine should also be checked for strangulation through a small defect which usually occurs due to edema of the eviscerated contents.

The treatment of such intestinal eviscerations involves prompt resuscitation, exclusion of other injuries, followed by early and careful laparotomy which allows the best opportunity to make an uneventful recovery. Immediate laparotomy is warranted when hemodynamic instability, the presence of peritonitis, evisceration, or impalement injuries are present in the patient.

It is important to recognize that local wound exploration must be technically adequate; a simple probing of the stab wound is not reliable to rule out the peritoneal violation, adequate exposure of the wound is required to follow the track of the stab [9]. If the peritoneum is breached, the patient should be admitted and kept under observation with regular clinical examination and the presence of visceral and bowel injury needs to be ruled out.

Delayed presentation, multiple abdominal organs injury, other extra-abdominal injuries and existing co-morbid diseases increase the morbidity and mortality in these patients. Prehospital assessment, well-equipped ambulances, early diagnosis, aggressive resuscitation and timely surgical intervention may improve the outcome in traumatic patients.

CT scan of the abdomen and pelvis has become indispensable for evaluation of stable patients after blunt abdominal trauma [10]. Some of the typical features that are diagnostic of hollow viscus perforation would include pneumoperitoneum, discontinuity of bowel wall, and extravasation of contrast materials. Other suggestive features would include free fluid without solid organ injury, bowel wall enhancement, bowel wall thickening, and bowel dilatation [11].

If possible, primary repair of the defect is preferable if technically feasible, rather than risking the possible complications of an anastomosis [12]. In our patient also primary repair was done with no postoperative complications and an uneventful recovery. He has been on regular follow-up and has remained asymptomatic and is doing well on all aspects.

\section{Conclusion}

Road traffic accidents are increasing by the day and so are the various organ injuries that occur along with them. Intestinal evisceration associated with road traffic accidents is a rare complication requiring an urgent exploratory laparotomy and our patient made a full and uneventful post-operative recovery. Timely intervention is of utmost importance in such a scenario. A prepared surgery team with an equipped operation room, availability of blood substitutes and the necessary investigations are all the important links in the management of the patient of bowel evisceration.

\section{References}

1. Teasdale G, Jennett B (1974) Assessment of coma and impaired consciousness. A practical scale. Lancet 2: 81-4.

2. Moore EE, Cogbill TH, Malangoni MA, Jurkovich GJ, Champion HR, et al. (1990) Organ injury scaling II: pancreas, duodenum, small bowel, colon, and rectum. J Trauma 30: 1427-9.

3. Erez I, Lazar L, Gutermacher M, Katz S (2001) Abdominal injuries caused by bicycle handlebars. Eur J Surg 167: $331-3$.

4. Cooper A, Barlow B, DiScala C, String D (1994) Mortality and truncal injury: the pediatric perspective. J Pediatr Surg 29: $33-8$.

5. Nagy K, Roberts R, Joseph K, An G, Barrett J (1999) Evisceration after abdominal stab wounds: is laparotomy required? J Trauma 47: 622-4.

6. Manohar K, Ramanaiah GV (2015) Abdominal Trauma in adults- its outcome- a prospective study in a teritiary health care centre in Andhra Pradesh. Indian J Appl Res 5: 35-8.

7. Dongo AE, Kesieme EB, Irabor DO, Ladikpo JK (2011) A Review of Posttraumatic Bowel Injuries in Ibadan. ISRN Surgery Article ID 478042.

8. Saghafinia M, Nafissi N, Motamedi MR, Motamedi MH, Hashemzade M, et al. (2010) Assesment and Outcome of 496 Penetrating Gastrointes-tinal Warfare Injuries. J Royal Army Med Corps 156: 25-7.

9. Rosenthal RE, Smith J, Walls RM, Chen H, Kline PP, et al. (1987) Stab wounds to the abdomen: failure of blunt probing to predict peritoneal penetration. Ann Emerg Med 16: 172-4.

10. Peitzman AB, Makaroun MS, Slasky BS, Ritter P (1986) Prospective study of computed tomography in initial management of blunt abdominal trauma. J Trauma 26: $585-92$.

11. Ng AK, Simons RK, Torreggiani WC, Ho SG, Kirkpatrick AW, et al. (2002) Intra-abdominal free fluid without solid organ injury in blunt abdominal trauma: an indication for laparotomy. J Trauma 52: 1134-40.

12. Kirkpatrick AW, Baxter KA, Simons RK, Germann E, Lucas CE, et al. (2003) Intra-abdominal complications after surgical repair of small bowel injuries: an international review. J Trauma 55: 399-406. 